\title{
Oxidation of deposited $\mathrm{Au}_{n}(n=2-13)$ on $\mathrm{SiO}_{2} / \mathrm{Si}$ : Influence of the $\mathrm{NaOH}(\mathrm{aq})$ treatment
}

\author{
Dong Chan Lim ${ }^{a}$, Rainer Dietsche ${ }^{\mathrm{b}}$, Gerd Ganteför ${ }^{\mathrm{b}}$, Young Dok Kim ${ }^{\mathrm{c}, *}$ \\ ${ }^{a}$ Department of Surface Technology, Korea Institute of Materials Science, Changwon 641-010, Republic of Korea \\ ${ }^{\mathrm{b}}$ Department of Physics, University of Konstanz, D-78457 Konstanz, Germany \\ ${ }^{c}$ Department of Chemistry, Sungkyunkwan University, 440-746 Cheoncheon-dong, Jangan-gu, Suwon, Gyeonggi-do, Republic of Korea
}

A R T I C L E I N F O

\section{Keywords:}

$\mathrm{Au}$

Cluster

Oxidation

$\mathrm{X}$-ray photoelectron spectroscopy

\begin{abstract}
A B S T R A C T
Au cluster anions consisting of 2-13 atoms were soft-landed on native-oxide-covered Si wafers. Reaction of soft-landed clusters with an atomic oxygen atmosphere was studied using X-ray photoelectron spectroscopy (XPS). $\mathrm{Au}_{5}, \mathrm{Au}_{7}$, and $\mathrm{Au}_{13}$ turned out to show pronounced inertness for Au-oxide formation. When the samples with deposited Au clusters were treated with aqueous $\mathrm{NaOH}$, the inert $\mathrm{Au}_{5}, \mathrm{Au}_{7}$, and $\mathrm{Au}_{13}$ clusters became reactive towards Au-oxide formation, whereas the other originally reactive clusters became inert. This result can be interpreted in terms of electronic modification of Au clusters by $\mathrm{Na}$, which was also evidenced by $\mathrm{Au} 4 \mathrm{f}$ and $\mathrm{Na}$ 1s core level shifts.
\end{abstract}

\section{Introduction}

Size-dependent changes of the properties of transition metal particles have attracted much attention due to the appearance of unique chemical and physical properties at certain sizes [1-4]. In order to shed light on the size-selectivity on the atom-by-atom basis, size-selected clusters have been studied. In the gas phase, mass of free clusters can be precisely selected using mass-spectrometry, and therefore, size-dependent changes of the physical and chemical properties of materials can be studied in detail [5-7]. More recently, not only free, but also deposited size-selected clusters have been studied, which can provide a deeper insight into the alteration of the cluster properties by the cluster-substrate interactions [8-11].

Mass-selected Au clusters deposited on oxide surfaces have been of particular interest due to their interesting activity in heterogeneous catalysis. Au clusters with certain sizes are reactive for heterogeneously-catalyzed reactions such as CO-oxidation. Au clusters consisting of 8-20 atoms on $\mathrm{MgO}$ turned out to be reactive for CO-oxidation, whereas smaller cluster are not [8]. It was suggested that the charge transfer between the Au and F centers on $\mathrm{MgO}$ should be crucial for enhancement of catalytic activity [8]. On $\mathrm{TiO}_{2}, \mathrm{Au}_{3}$ and $\mathrm{Au}_{7}$ turned out to be reactive towards $\mathrm{CO}$-oxidation [9]. On silica surfaces, pronounced inertness towards Au-oxide formation for some odd-numbered Au clusters such as $\mathrm{Au}_{5}$ and $\mathrm{Au}_{7}$ were shown [10]. Using cavity ring down spectroscopy (CRDS), it

\footnotetext{
* Corresponding author. Tel.: +82 31299 4564; fax: +82 312907075

E-mail address: ydkim91@skku.edu (Y.D. Kim).
}

was suggested that $\mathrm{Au}$ is bound to non-bridging oxygen sites of silica surfaces, which may change the charge state of Au, thereby influencing its chemical properties [11].

In the present work, Au clusters consisting of 2-13 atoms were deposited on native-oxide-covered Si wafers, and their chemical properties studied by investigating the oxidation/reduction behaviors. For Au clusters smaller than $\mathrm{Au}_{9}$, an even-odd behavior can be found, whereby the odd-numbered clusters are generally more inert than the even-numbered neighbors when they are exposed to an atomic oxygen environment [10]. Among the odd-numbered clusters, 5 and 7 are the magic numbers with a pronounced inertness towards oxidation; however, this even-odd pattern was absent for larger clusters. For the Au clusters consisting of more than 8 atoms, $\mathrm{Au}_{13}$ was the only inert species. Upon $\mathrm{NaOH}$ solution treatment, clusters inert towards oxidation became more reactive, whereas the other originally reactive neighbors became less reactive. This result can be interpreted in terms of electronic modification of the Au clusters by Na, which was also evidenced by Au $4 \mathrm{f}$ and $\mathrm{Na} 1 \mathrm{~s}$ core level shifts.

\section{Experimental}

All the measurements were performed under ultrahigh vacuum (UHV) conditions $[10,12]$. For X-ray photoelectron spectroscopy (XPS), a concentric hemispherical analyzer (CHA) and an X-ray source with an $\mathrm{Al}$ target $(\mathrm{K} \alpha$, photon energy $=1486.6 \mathrm{eV})$ were used. For acquisition of each Au $4 \mathrm{f}$ spectrum, $1 \mathrm{~h}$ was required. Si wafers were chemically etched using a mixture of three different acids and water $\left(\mathrm{H}_{3} \mathrm{PO}_{4}, \mathrm{HNO}_{3}, \mathrm{CH}_{3} \mathrm{COOH}\right.$, and $\mathrm{H}_{2} \mathrm{O}$ with a volume 
ratio of $3: 3: 23: 1)$. The chemical etching was done in order to increase the number of defect sites of the silica surface, thereby reducing the diffusion of the clusters on the surface, which can cause their agglomeration. For the oxidation experiments, the backsides of the samples were exposed to a hot Pt-filament and, at the same time, the chamber was filled with molecular oxygen $\left(8 \times 10^{-5} \mathrm{mbar}\right)$, which is known to create atomic or excited molecular oxygen [13]. Using this method, metal surfaces, which do not react with molecular oxygen, can be oxidized. After these atomic oxygen treatments, no Pt could be detected using XPS. The exposure time of each sample to atomic oxygen was $30 \mathrm{~min}$.

For the creation of Au cluster anions, a magnetron-sputtersource, originally designed by Prof. Haberland's group at the University of Freiburg, Germany, was used [14]. After extracting the ion beam into a vacuum, the cluster anions were accelerated to $1 \mathrm{kV}$. Mass separation was done by means of a $30^{\circ}$ sector magnet with a resolution of $m / \Delta m=20$. In front of the sample, the clusters were decelerated to the desired deposition energy by applying the corresponding voltage to the sample. The number of clusters deposited on the surface can be counted by measuring the sample current during deposition. All the clusters were softlanded on the surface in which a kinetic energy of less than $0.6 \mathrm{eV}$ per atom was used (most of the clusters had a kinetic energy less than $0.2 \mathrm{eV}$ per atom during deposition). For deposition of the Au cluster anions on the substrate, $\sim 30 \mathrm{~min}$ were required. The measured sample current was about $0.4 \mathrm{nA}$ during deposition. $2 \times 10^{12}$ clusters were deposited on each sample. Considering that the diameter of the area of the cluster deposition is estimated to be $3 \mathrm{~mm}$, the cluster density is suggested to be roughly $3 \times 10^{13}$ clusters $/ \mathrm{cm}^{2}$. This corresponds to less than $10 \%$ of a monolayer equivalent $[10,12]$.

After the clusters had been deposited on the surface, the samples were immersed into distilled water or aqueous $0.1 \mathrm{M} \mathrm{NaOH}$ (purity: 99\%) for 10 min [15]. After these treatments, the samples were immediately inserted into the vacuum system and oxidation/reduction experiments and XPS-analyses performed. For reduction, the surfaces were exposed to 10,000 Langmuir $\left(L=1 \times 10^{-6}\right.$ torr $\left.\times 1 \mathrm{~s}\right)$ of $\mathrm{CO}$ at room temperature.

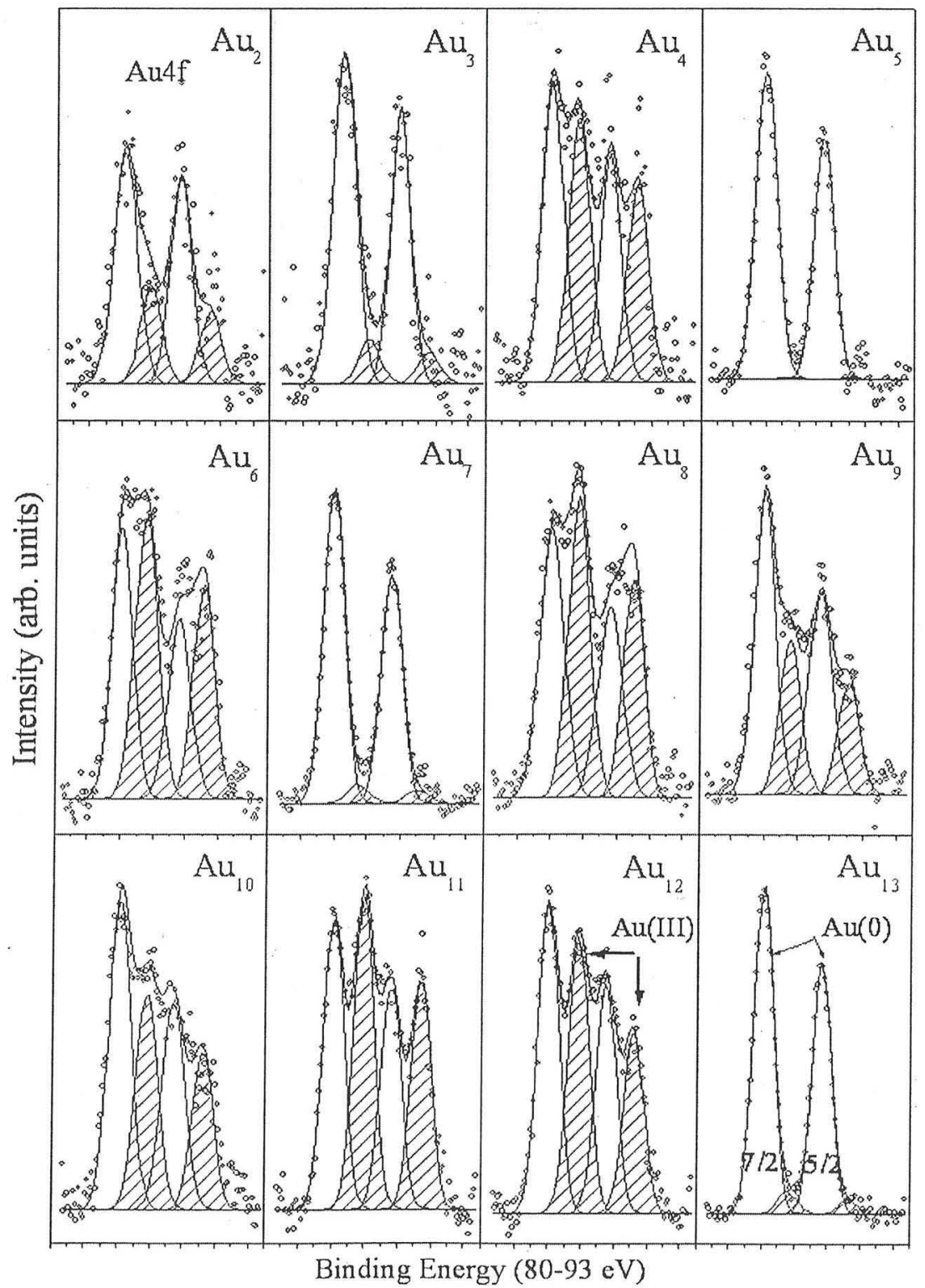

Fig. 1. Au $4 \mathrm{f}$ level spectra of deposited Au clusters consisting of 2-13 atoms after atomic oxygen exposure are summarized. The shadowed regions correspond to the Au(III) species. 


\section{Results and discussion}

Mass-selected Au cluster anions consisting of 2-13 atoms were soft-landed on native-oxide-covered Si wafer surfaces. Subsequently, the samples were exposed to atomic oxygen environments. Fig. 1 shows the Au $4 \mathrm{f}$ level spectra obtained after atomic oxygen treatment of each sample. The peaks of the doublet structure of $\mathrm{Au}(0)$ were centered at 84 and $87 \mathrm{eV}$, respectively, as in bulk $\mathrm{Au}$, whereas the $\mathrm{Au}(\mathrm{III})$ species showed a positive core level shift of $1.5 \mathrm{eV}$ with respect to the $\mathrm{Au}(0)$ state.

With increasing the number of $\mathrm{Au}$ atoms in a cluster, the ratio between $\mathrm{Au}(\mathrm{III})$ and $\mathrm{Au}(0)$ strongly varied (Fig. 2). For $n=2-9$, an even-odd alteration could be found where the even-numbered clusters showed higher intensities of $\mathrm{Au}(\mathrm{III})$ peaks with respect to the $A u(0)$ peaks than in the case of the odd-numbered neighbors. In particular, an even-odd variation was pronounced for $n=4-9$, where $\mathrm{Au}_{5}$ and $\mathrm{Au}_{7}$ showed an extraordinarily high inertness towards Au-oxide formation. For Au clusters consisting of more than 9 atoms, the even-odd behavior disappeared. Oxidation of $\mathrm{Au}_{11}$ was more facile than that of other directly neighboring clusters. In contrast to $\mathrm{Au}_{11}, \mathrm{Au}_{13}$ was absolutely inert towards oxidation under our experimental conditions. For the samples with complete inertness of $\mathrm{Au}$ towards oxidation $\left(\mathrm{Au}_{5}, \mathrm{Au}_{7}\right.$ and $\left.\mathrm{Au}_{13}\right)$, one can suggest that Au clusters survived as individual cluster after deposition with only minor fragmentation and sintering, since the chemical properties of these clusters are unique and different from those of other neighbors. For other clusters, it is not clear from the result in Fig. 1, whether deposited clusters partially underwent fragmentation and sintering, or not.

The samples prepared in the same way as those in Fig. 1 were immersed into aqueous $0.1 \mathrm{M} \mathrm{NaOH}$ and reinserted into the UHV system. Subsequently, the samples were exposed to the atomic oxygen environments (Figs. 3 and 4). Fig. 3 shows the Au 4 f level spectra acquired after the atomic oxygen treatment of the $\mathrm{NaO}-$ $\mathrm{H}(\mathrm{aq})$-treated samples. We focused on those Au clusters, showing pronounced inertness in Fig. $1\left(\mathrm{Au}_{5}, \mathrm{Au}_{7}\right.$ and $\left.\mathrm{Au}_{13}\right)$, warranting survival of individual clusters upon deposition, and their direct neighbors. One can conclude that the originally inert $\mathrm{Au}_{5}, \mathrm{Au}_{7}$, and $\mathrm{Au}_{13}$ became more reactive because these clusters showed higher relative intensity of the $\mathrm{Au}$ (III) peak compared to the case prior to $\mathrm{NaO}-$ $\mathrm{H}(\mathrm{aq})$ treatment. In contrast, the other originally reactive clusters became less reactive towards $\mathrm{Au}$-oxide formation.

$\mathrm{Au} 4 \mathrm{f}$ spectra of the deposited Au clusters exhibited negative core level shifts upon NaOH-treatment by $0.2-0.5 \mathrm{eV}$ (Fig. 5). The core level shift was small, but could be found for all clusters studied here. The $\mathrm{Na} 1 \mathrm{~s}$ spectra of the $\mathrm{Au}_{8}$-deposited sample with the $\mathrm{NaOH}$-treatment are compared with the $\mathrm{Na} 1 \mathrm{~s}$ spectrum of a Si wafer without $\mathrm{NaOH}$ (aq)-treated Au (Fig. 6). When Au was absent on

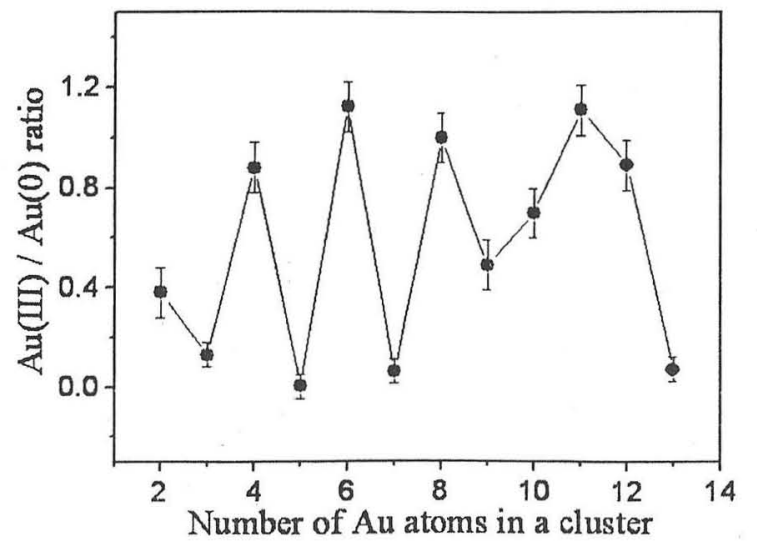

Fig. 2. Relative intensity ratio of $\mathrm{Au}(\mathrm{III})$ and $\mathrm{Au}(0)$ for each cluster is summarized. the surface, Na showed a peak centered at about $1072 \mathrm{eV}$. When the Au-deposited sample was treated with $\mathrm{NaOH}$, an additional shoulder at a higher binding energy could be identified in the $\mathrm{Na}$ $1 \mathrm{~s}$ spectrum, possibly indicating $\mathrm{Na}$ atoms directly attached to Au. Change in Na 1s signal is rather small, since only a part of the surface was covered by Au, whereas Na covered whole the surface. Our XPS spot was larger than the Au cluster spot. The change in the $\mathrm{Na} 1 \mathrm{~s}$ spectrum by $\mathrm{Au}$ is small, but reproducible in repeated experiments. Coexistence of $\mathrm{Na}$ and $\mathrm{Au}$ resulted in a positive and a negative $\mathrm{Na} 1 \mathrm{~s}$ and $\mathrm{Au} 4 \mathrm{f}$ level shift, respectively. From these results of the core level shifts, one can suggest that interactions" between $\mathrm{Na}$ and $\mathrm{Au}$ result in a charge transfer from $\mathrm{Na}$ to $\mathrm{Au}$.

Considering electronic structure, a closed-shell electronic configuration with an even number of valence shell electrons can be magic [5-7]. Depending on preparation methods, both electronic and geometric magic numbers can appear. In the gas phase studies,

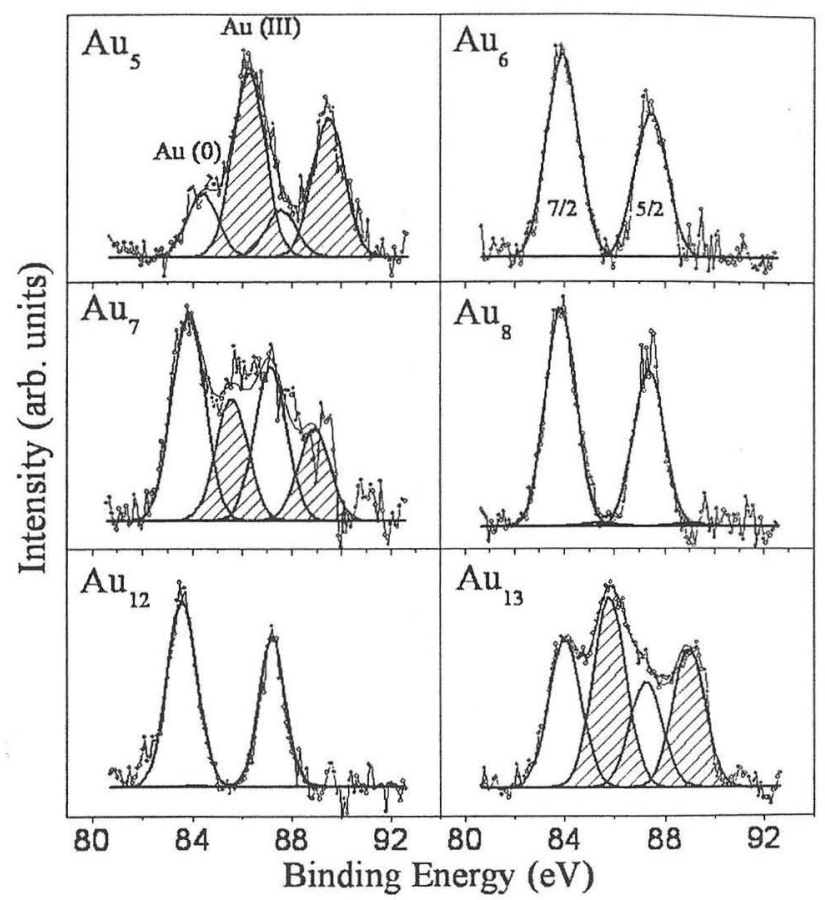

Fig. 3. Au $4 \mathrm{f}$ level spectra of originally inert clusters and non-inert neighbors are compared, which were taken after the $\mathrm{NaOH}(\mathrm{aq})$ treatment and subsequent atomic oxygen exposure.

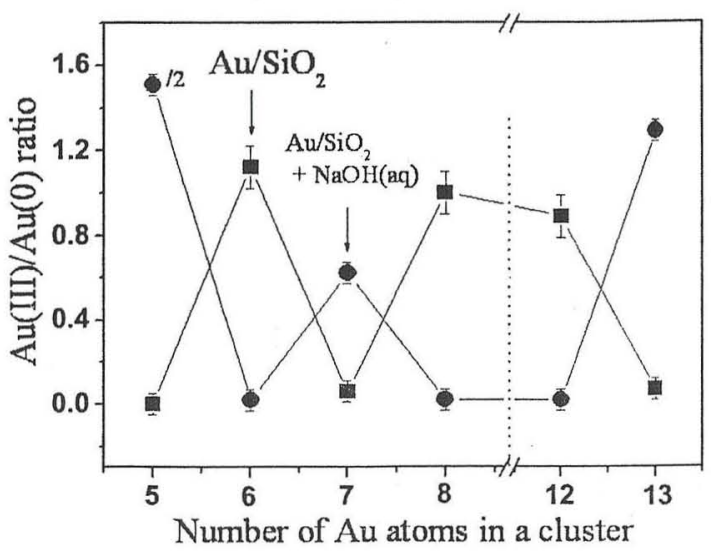

Fig. 4. Relative intensity ratio of $\mathrm{Au}(\mathrm{III})$ and $\mathrm{Au}(0)$ for atomic-oxygen-treated $\mathrm{Au}_{5}$, $\mathrm{Au}_{6}, \mathrm{Au}_{7}, \mathrm{Au}_{8}, \mathrm{Au}_{12}$, and $\mathrm{Au}_{13}$, with and without $\mathrm{NaOH}(\mathrm{aq})$ treatment, is summarized 


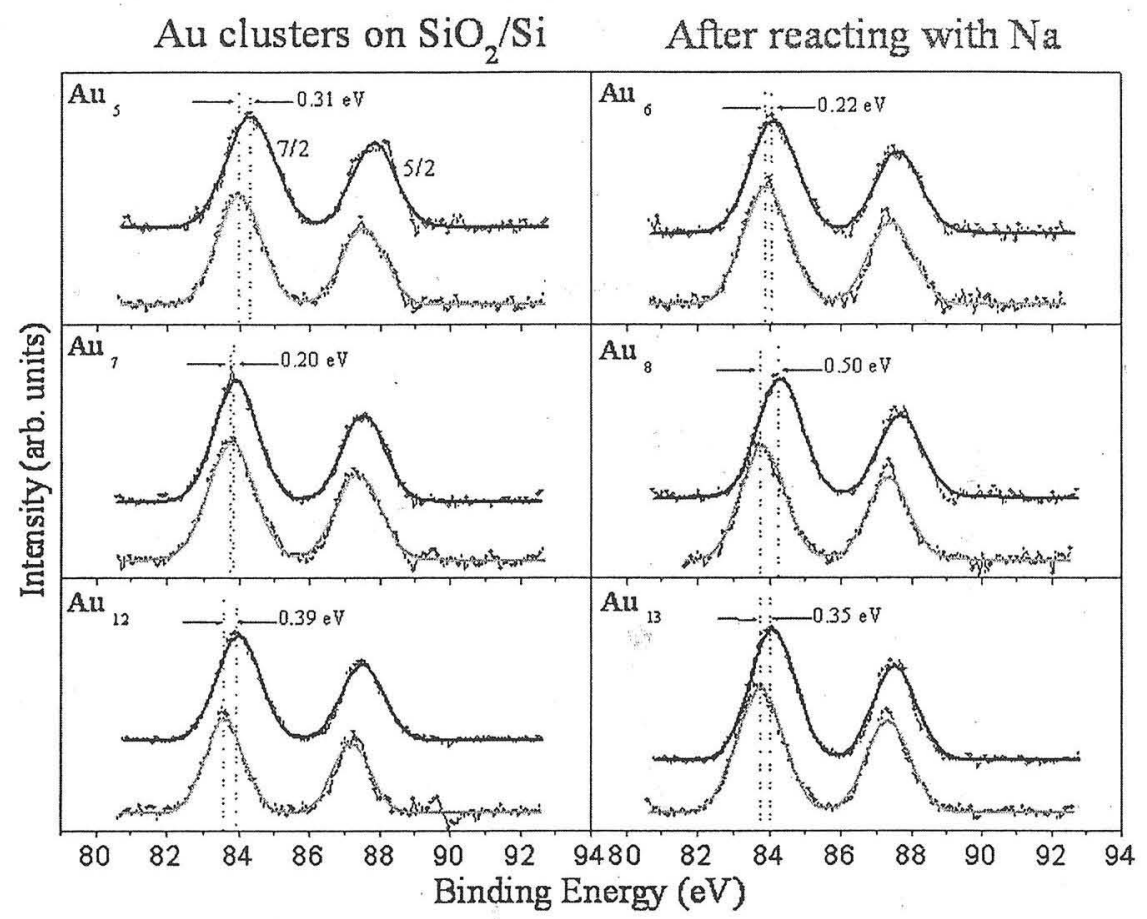

Fig. 5. Au $4 \mathrm{f}$ level spectra before and after the $\mathrm{NaOH}(\mathrm{aq})$ treatment are compared, in which negative core level shifts upon $\mathrm{NaOH}-\mathrm{treatment}$ are apparent.

odd-numbered Au cluster anions were shown to be less reactive than other even-numbered neighbors towards reactivity of molecular oxygen adsorption, due to lower electron affinity of odd-numbered cluster neutrals [5-7]. This result demonstrates that cluster reactivity is governed by electronic structures. Considering that addition of $\mathrm{NaOH}$ can electronically modify Au clusters, thereby changing the cluster reactivity, it can be proposed that the reactivity of the soft-landed clusters in our study is governed more by the electronic properties of Au clusters. For wet-chemically prepared

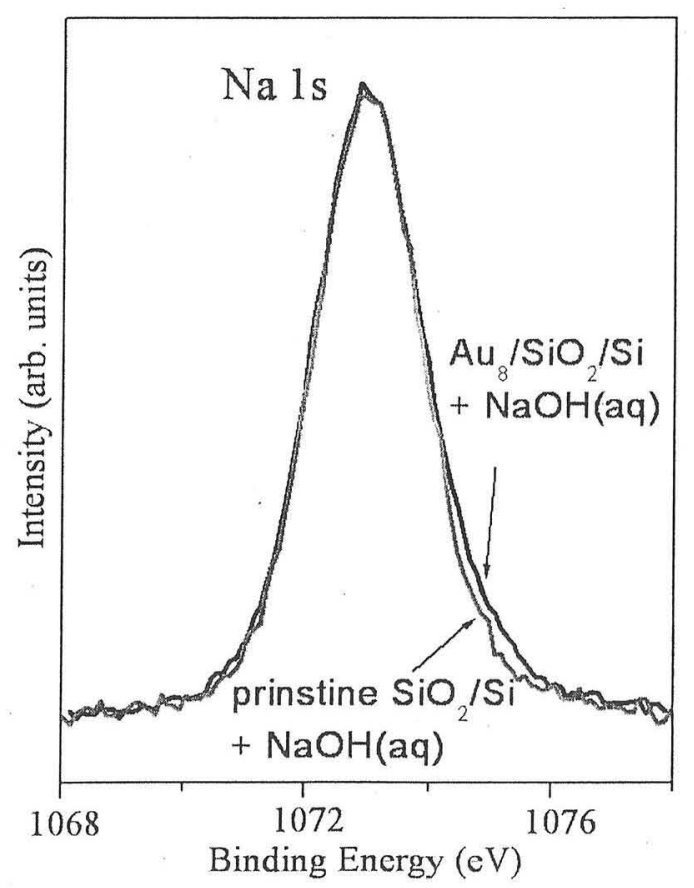

Fig. 6. $\mathrm{Na} 1 \mathrm{~s}$ spectrum collected from a $\mathrm{Au}_{8}$-covered $\mathrm{Si}$ wafer after $\mathrm{NaOH}(\mathrm{aq})$ treatment (black) is compared with that of a pristine Si wafer after the same $\mathrm{NaOH}$ treatment (gray)
Au clusters, in contrast, $\mathrm{Au}_{55}$ with a closed-shell geometry was shown to be the only inert species towards Au-oxide formation; however, for $\mathrm{Au}_{n}$ with $n<14$, it has been demonstrated that the cluster geometry does not correspond to a closed-shell structure [16-18]. Our results mentioned above suggest that the chemical activity of deposited clusters is greatly influenced by electronic modification, implying an importance of electronic structure for determining chemical activity of deposited clusters. It is still not completely clear why the odd-numbered clusters are generally more reactive than even-numbered clusters towards Au-oxide formation. The Si wafer is kept at deposition potential during deposi-

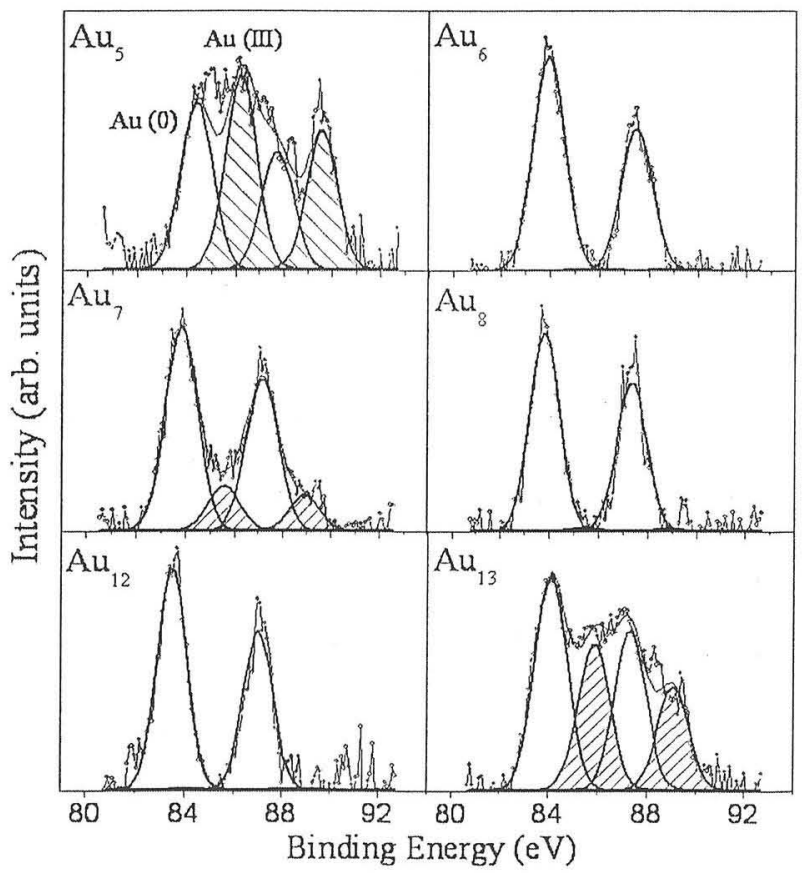

Fig. 7. Au $4 \mathrm{f}$ level spectra of the samples in Fig. 3 collected after CO exposures. 
tion, and additional charge of the deposited cluster flows to ground. This electron flow is measured in order to estimate the number of Au clusters deposited. It can be tentatively suggested that the deposited Au clusters are not charged, and thus, in a simple electronic model, even-numbered clusters with closed shell configurations should be more inert than odd-numbered clusters. One may argue that the Au clusters on the surface are either negatively or positively charged due to the metal-support interaction. Considering that $\mathrm{Na}$ renders Au more negatively charged, it is less likely that Au is already partially negatively charged on the Si wafer without Na. A positive charging of Au clusters on silica is not supported by our XPS results. Theoretical studies about interaction between Si, Au clusters and Na may further shed light on this issue.

When the oxidized Au clusters in Fig. 3 were exposed to $\mathrm{CO}$, reduction of the Au-oxide could be found; however, large amounts of oxygen still remained un-reacted (Fig. 7). The un-reacted Auoxide species are attributed to the species existing in the subsurface regime. When Au was oxidized, not only the surface topmost layer, but also the deeper layers, could be partially oxidized. Upon $\mathrm{CO}$ exposure, the Au-oxide at the deeper layers could remain unreacted.

\section{Conclusion}

Au clusters consisting of 2-13 atoms were deposited on silica and their electronic and chemical properties studied using XPS. Some odd-numbered clusters were highly inert towards reaction with the atomic oxygen atmosphere. Upon $\mathrm{NaOH}(\mathrm{aq})$ treatment, the inert clusters became more reactive, whereas the other neighboring clusters became less reactive. This result could be interpreted in terms of modification of the electronic structures of the $\mathrm{Au}$ clusters by $\mathrm{Na}$, which could also be evidenced by the Au $4 \mathrm{f}$ and $\mathrm{Na}$ 1s level shifts.

\section{Acknowledgements}

Deutsche Forschungsgemeinschaft (DFG) is acknowledged for its financial support through the Sonderforschungsbereich (SFB 513 program (A15)). This work was supported by a Korea Research Foundation Grant funded by the Korean Government (KRF-2006000-(00003).

\section{References}

[1] M. Haruta, S. Tsubota, H. Kobayashi, M. Kageyama, J. Genet, B. Delmon, J. Catal. 144 (1993) 175.

[2] M. Valden, X. Lai, D.W. Goodman, Science 281 (1998) 1647.

[3] B.C. Guo, K.P. Kerns, A.W. Castleman Jr., Science 255 (1992) 1411.

[4] B.V. Reddy, S.N. Khanna, P. Jena, Science 258 (1992) 1640.

15] T.H. Lee, K.M. Ervin, J. Phys. Chem. 98 (1994) 10023.

[6] Y.D. Kim, Int. J. Mass Spectrom. 238 (2004) 17.

[7] D. Stolcic, M. Fischer, G. Ganteför, Y.D. Kim, Q. Sun, P. Jena, J. Am. Chem. Soc. 125 (2003) 2848.

[8] A. Sanchez, S. Abbet, U. Heiz, W.-D. Schneider, H. Häkkinen, R.N. Barnett, U. Landman, J. Phys. Chem. A 103 (1999) 9573.

[9] S. Lee, C. Fan, T. Wu, S.L. Anderson, J. Am. Chem. Soc. 126 (2004) 5682.

[10] D.C. Lim, R. Dietsche, M. Bubek, G. Ganteför, Y.D. Kim, ChemPhysChem 7 (2006) 1909.

[11] J.M. Antonietti, M. Michalski, U. Heiz, H. Jones, K.H. Lim, N. Rosch, A. Dewl Vitto, G. Pacchioni, Phys. Rev. Lett. 94 (2005) 213402.

[12] D.C. Lim, R. Dietsche, M. Bubek, T. Ketterer, G. Gantefoer, Y.D. Kim, Chem. Phys. Lett. 439 (2007) 364

[13] N.D.S. Canning, D. Outka, RJ. Madix, Surf. Sci. 141 (1984) 240.

[14] H. Haberland, M. Mall, M. Moseler, Y. Quiang, T. Reiners, Y. Thurner, J. Vac. Sci. Technol. A 12 (1994) 2925.

[15] D.C. Lim, R. Dietsche, G. Ganteför, Y.D. Kim, Chem. Phys. Lett. 457 (4-6) (2008) 391.

[16] H.G. Boyen, G. Kastle, F. Weigl, B. Koslowski, C. Dietrich, P. Ziemann, J.P. Spatz, S. Riethmuller, C. Hartmann, M. Moller, G. Schmid, M.G. Garnier, P. Oelhafen, Science 207 (2002) 1533.

[17] H.G. Boyen, A. Ethirajan, G. Kastle, F. Weigl, P. Ziemann, G. Schmid, M.G. Garnier, M. Buttner, P. Oelhafen, Phys. Rev. Lett. 94 (2005) 0168044.

[18] F. Furche, R. Ahlrichs, P. Weis, C. Jacob, S. Gilb, T. Bierweiler, M.M. Kappes, J. Chem. Phys. 117 (2002) 6982 